\title{
Eventos do processo de infecção de Colletotrichum gloeosporioides inoculados em folhas de Coffea arabica L.
}

\author{
Josimar Batista Ferreira $^{1 *}$, Mario Sobral de $\mathrm{Abreu}^{2}$, Eduardo Alves², Igor Souza Pereira ${ }^{3}$, Katiúcia Dias Fernandes ${ }^{2}$
}

${ }^{1}$ Universidade Federal do Acre, UFAC, Campus Floresta, Laboratório de Fitopatologia, CCBN, CEP 69980-000, Estrada Canela Fina s/n, Cruzeiro do Sul, AC; ${ }^{2}$ Universidade Federal de Lavras, UFLA, Depto. Fitopatologia, C. P. 3037, CEP 37200-000, Campus Universitário, Lavras, MG. ${ }^{3}$ Empresa de Pesquisa Agropecuária de Minas Gerais, EPAMIG, FESR, CEP 35715-000, Rod. MG 424 Km 64, S/N, Prudente de Morais, MG. *Parte da Tese de Doutorado do primeiro autor apresentada à Universidade Federal de Lavras, Bolsista do CNPq.

Autor para correspondência: Eduardo Alves (ealves@ufla.br)

Data de chegada: 25/05/2007. Aceito para publicação em: 03/03/2009.

1489

\section{RESUMO}

Ferreira, J. B.; Abreu, M. S.; Alves, E.; Pereira, I. S.; Fernandes, K. D. Eventos do processo de infecção de Colletotrichum gloeosporioides inoculados em folhas de Coffea arabica L. Summa Phytopathologica, v.35, n.4, p.273-281, 2009

O presente trabalho teve por objetivo obter informações sobre os eventos de pré-penetração, penetração e colonização de isolados de C. gloeosporioides, obtidos de mangueira e cafeeiro, quando inoculados em folhas de cafeeiros (Coffea arabica L.) da cultivar Catucaí Vermelho. As folhas foram selecionadas, padronizadas e lavadas, demarcando-se áreas circulares de $0,5 \mathrm{~cm}$ de diâmetro na face abaxial, inoculando-se uma alíquota de $20 \mu \mathrm{L}$ da suspensão de conídios. Utilizouse um isolado obtido de mangueira e dois isolados obtidos de cafeeiro com mancha manteigosa. Realizaram-se avaliações com 3, 6, 8, 12, $24,36,48,72,96,144$ e 240 horas após a inoculação (hai). Todos os materiais foram processados e observados em microscópico eletrônico de varredura. Os conídios de todos os isolados aderiram freqüentemente nas depressões das células da epiderme e células-guarda dos estômatos, formando septo antes da germinação. A penetração, na maior parte, se deu por via direta e algumas vezes por estômatos. Isolados de cafeeiro germinaram em folhas de 6 a 8 hai, produzindo apressórios 12 hai e acérvulos de 96 a 144 hai. $\mathrm{O}$ isolado de mangueira germinou de 6 a 8 hai com formação de apressório de 8 a 12 hai e produziu novos conídios diretamente em hifas conidiogênicas. Não foi observada a formação acérvulos para este isolado.

Palavras-chave adicionais: Mancha manteigosa, antracnose, microscopia eletrônica de varredura.

\begin{abstract}
Ferreira, J. B.; Abreu, M. S. de; Alves, E.; Pereira, I. S.; Fernandes, K. D. Events of the infection process of Colletotrichum gloeosporioides on leaves of Coffea arabica L. Summa Phytopathologica, v.35, n.4, p.273-281, 2009

The present study was carried out with the objective to provide information on the pre-penetration, penetration and colonization events of isolates of Colletotrichum gloeosporioides from mango and coffee, when inoculated in coffee leaves. The cultivar Catucaí Vermelho was used in all experiments. Coffee leaves were selected, standardized and washed in sterile water. After that, circular areas of $0.5 \mathrm{~cm}$ in diameter were marked on the undersurface of the leaves. In the center of each circular area, $20 \mu \mathrm{L}$ of spore suspension was deposited. One isolate from mango and two from coffee presenting blister spot were used in all trials. The time course of the experiments was $3,6,8,12,24,36,48,72,96,144$ and 240 hours after inoculation

(h.a.i.). All materials were analyzed in scanning electron microscopy. The conidia of all isolates adhered more frequently on the plant tissue depressions and guard-cells forming septum before germination. The most common penetration via was the direct, although some penetration through stomata also occurred. Isolates obtained from blister spot symptoms germinated on coffee leaves after 6 to 8 h.a.i., producing appressoria after 12 h.a.i., and acervuli after 96 to 144 h.a.i. The isolate from mango germinated on the coffee leaves after 6 to 8 h.a.i. and formed appressoria after 8 to 12 h.a.i., but was unable to form acervuli, bearing conidia directly from conidiogenous hypha on the mycelium.
\end{abstract}

Keywords: Blister spot, anthracnose, scanning electron microscopy.

Em cafeeiro (Coffea arabica L.), no Brasil, algumas espécies de Colletotrichum são encontradas, sendo algumas patogênicas ou endofíticas. Dentre estas espécies destaca-se o C. gloeosporioides, associado aos sintomas da antracnose nas folhas, frutos, mancha manteigosa e seca de ponteiros (19).

Estudos do patossistema Colletotrichum spp. e cafeeiro no Brasil foram dirigidos, até o momento, à etiologia do patógeno, à patogenicidade, à caracterização de isolados, sobretudo daqueles que podem causar a mancha manteigosa, e a aspectos histopatológicos de ramos de cafeeiros atacados por Colletotrichum spp. (20;24). $\mathrm{O}$ ataque de Colletotrichum spp. a ramos de cafeeiros causou alterações na estrutura normal do caule, como o espessamento das paredes celulares da epiderme e do córtex, com a presença de compostos fenólicos, formação de câmbio (felogênio) e num estádio mais avançado de infecção, a formação de periderme (24). Segundo Pereira et al. (20), a seca descendente de ramos de cafeeiros apresentando sintomas da 
mancha manteigosa, deve-se à obstrução de vasos e parênquima do xilema por estruturas de $C$. gloeosporioides.

Deste modo, o conhecimento da biologia do fungo e dos detalhes que ocorrem nos diferentes processos e subprocessos do ciclo da doença, permitem caracterizar as mudanças ou danos histopatológicos ocasionados pelo fungo nas células de interações compatíveis. Da mesma forma, a compreensão dos eventos de pré-penetração, de como o patógeno infecta e coloniza o hospedeiro e como a planta estabelece mecanismos de resistência pré e pós-formados, é fundamental para o estabelecimento de medidas de controle da doença $(3,13,17,18,22$, 23).

O tempo de duração, a forma de colonização de Colletotrichum spp. e a existência de período latente, principalmente em frutos $(8,9$, 11), têm sido estudados. Espécies desse gênero, tidos como modelos para processos de infecção (3), têm diversas estratégias de colonização dos tecidos, que vão de hemibiotrofia intracelular em $C$. lindemuthianum, C. gloeosporioides, C. graminicola, C. orbiculare e C. truncatum; a intramural subcuticular, relatada para C. capsici, $C$. circinans, $C$. gloeosporioides e $C$. phomoides e há espécies que exibem ambas, infecção hemibiotrófica intracelular e intramural subcuticular, como C. gloeosporioides (13).

Este estudo foi realizado com o objetivo de obter informações sobre os eventos de pré-penetração, penetração e colonização, por meio da microscopia eletrônica de varredura, de isolados $C$. gloeosporioides de cafeeiro e mangueira quando inoculados em folhas de cafeeiro.

\section{MATERIAL E MÉTODOS}

Os experimentos foram conduzidos nos Laboratórios de Diagnose e Controle de Enfermidades de Plantas e de Microscopia Eletrônica e Análise Ultra-estrutural (LME) no Departamento de Fitopatologia da Universidade Federal de Lavras (UFLA), Lavras, MG.

\section{Obtenção de isolados de $\boldsymbol{C}$. gloeosporioides}

Utilizou-se três isolados de C. gloeosporioides. Dois isolados (denominação: J-I2 e J-I6) foram provenientes de cafeeiros da cultivar Catucaí Vermelho (em seleção) com sintomas da mancha manteigosa e um isolado (denominação: IM) foi proveniente de mangueira (Mangifera indica L.) com sintomas de antracnose foliar. Foram coletadas folhas de mangueira com sintomas da antracnose, ramos (hastes) e hipocótilos de cafeeiros com sintomas da mancha manteigosa. Fez-se o isolamento em meio MEA 2\% (extrato de malte-ágar), incubando por 7 dias em câmara de crescimento a temperatura de $23 \pm 2{ }^{\circ} \mathrm{C}$ e fotoperíodo de 12 horas. Após constatação de fungos do gênero Colletotrichum, as colônias foram purificadas e em seguida foi realizada sua identificação por meio de características morfológicas e culturais, obtendo-se as culturas monospóricas de C. gloeosporioides.

\section{Seleção de material vegetativo de café para estudos histopatológicos em folhas \\ Utilizou-se a cultivar Catucaí Vermelho. Foram coletadas folhas sadias de plantas com sintomas de mancha manteigosa e folhas de plantas sem sintomas da doença, todas colhidas no terceiro par de folhas, em ramos plagiotrópicos no terço médio das plantas.}

\section{Preparo do material para inoculações}

As folhas colhidas foram padronizadas, selecionadas, lavadas em solução de detergente neutro a $0,5 \%$ e em seguida, enxaguadas por duas vezes com água destilada esterilizada para a retirada do excesso do detergente e finalmente secas em papel de filtro. Demarcaram-se na face abaxial das folhas, oito áreas circulares de aproximadamente 0,5 $\mathrm{cm}$ de diâmetro, sendo quatro de cada lado da nervura central na face abaxial. Utilizou-se caneta de marca permanente para demarcação, dando uma orientação da região da inoculação.

As folhas lavadas e secas, já com o ponto de inoculação demarcado, foram acondicionadas em bandejas forradas com espuma de poliuretano (2x40x23 cm) e papel germitest, ambos umedecidos com água destilada e esterilizada, proporcionando a manutenção da umidade e cobertas com papel alumínio perfurado (4). Cobriu-se o ápice foliar e o pecíolo com algodão umedecido por água esterilizada, a fim de se manter a característica fisiológica foliar uma vez que as avaliações estenderam por vários dias. Em seguida, inocularam-se os isolados.

\section{Inoculações e avaliações}

As áreas demarcadas das folhas foram inoculadas com alíquotas de $20 \mu \mathrm{L}$ da suspensão de conídios $\left(2 \times 10^{6}\right.$ conídios $\left.\mathrm{mL}^{-1}\right)$. Após a inoculação, as folhas foram acondicionadas em bandejas plásticas e mantidas em condição de câmara úmida e temperatura de $23 \pm 2^{\circ} \mathrm{C}$. As coletas para avaliações foram realizadas nos tempos de 3, 6, 8, 10, 12, 18, 24, 36, 48, 72, 96, 144 e 240 horas após a inoculação.

\section{Preparo e observação das amostras - microscopia eletrônica de varredura (MEV)}

A preparação das amostras foi realizada no laboratório de Microscopia e Análise Ultraestrutural (LME), no Departamento de Fitopatologia da Universidade Federal de Lavras (MG), conforme protocolo de rotina do laboratório (1).

As amostras devidamente preparadas e identificadas foram examinadas ao microscópio de varredura LEO EVO 40XVP. As imagens foram geradas e registradas digitalmente, utilizando o software Leo User Interface, tendo sido geradas diversas eletromicrografias para cada amostra nas condições de trabalho de $20 \mathrm{Kv}$ e distância de trabalho variando de 9 a $12 \mathrm{~mm}$. As imagens foram gravadas e processadas no Software Photopaint, do pacote Corel Draw 12.

\section{RESULTADOS E DISCUSSÃO}

Eventos da infecção de Colletotrichum gloeosporioides em cafeeiro - isolado mancha manteigosa

Os conídios dos isolados de C. gloeosporioides da mancha manteigosa, freqüentemente, aderiram nas depressões das células da epiderme e das células-guarda dos estômatos (Figuras 1A e 2A). Resultados semelhantes foram encontrados por Lins et al. (12), quando isolados de Colletotrichum spp. foram inoculados em folhas de plântulas de cafeeiro produzidas por cultura de embrião. Pereira et al. (20), quando inocularam hipocótilos de cafeeiros com $C$. gloeosporioides, isolado de cafeeiro com sintomas de mancha manteigosa, observaram uma maior aderência nas depressões e a correlação desta aderência com a topografia da epiderme dos hipocótilos inoculados.

Foi também observado três horas após a inoculação que ocorreu o intumescimento dos conídios, formando septo, devido à ocorrência de uma divisão mitótica do conídio, sendo que até três septos foram observados por conídio (Figuras 3A e 3B).

Lins et al. (12) verificaram, em hipocótilos de cafeeiro, a formação 

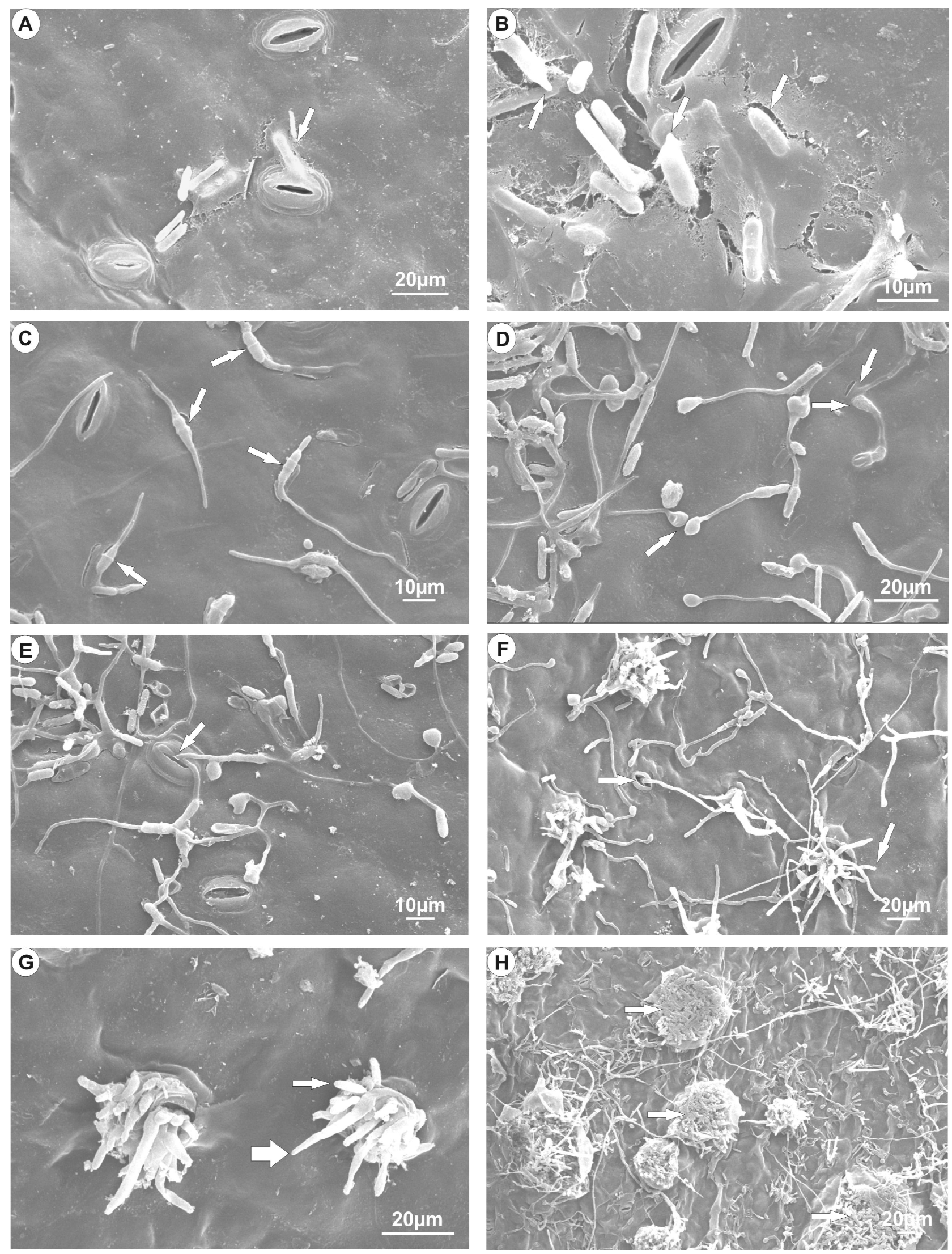

Figura 1. Eletromicrografias de varredura dos eventos de penetração, colonização e reprodução do isolado J-I2 de Colletotrichum gloeosporioides, obtido de folhas com sintomas de mancha manteigosa e inoculado em folhas de cafeeiro. A e B: aderência de conídios em depressões da folha (setas); C: germinação de conídios (setas); D: formação de apressórios (setas); E e F: penetração via estômato (setas); G: produção de acérvulos com conídios (seta) e formação de seta (seta larga) e H) massa de conídios em acérvulos (setas). 

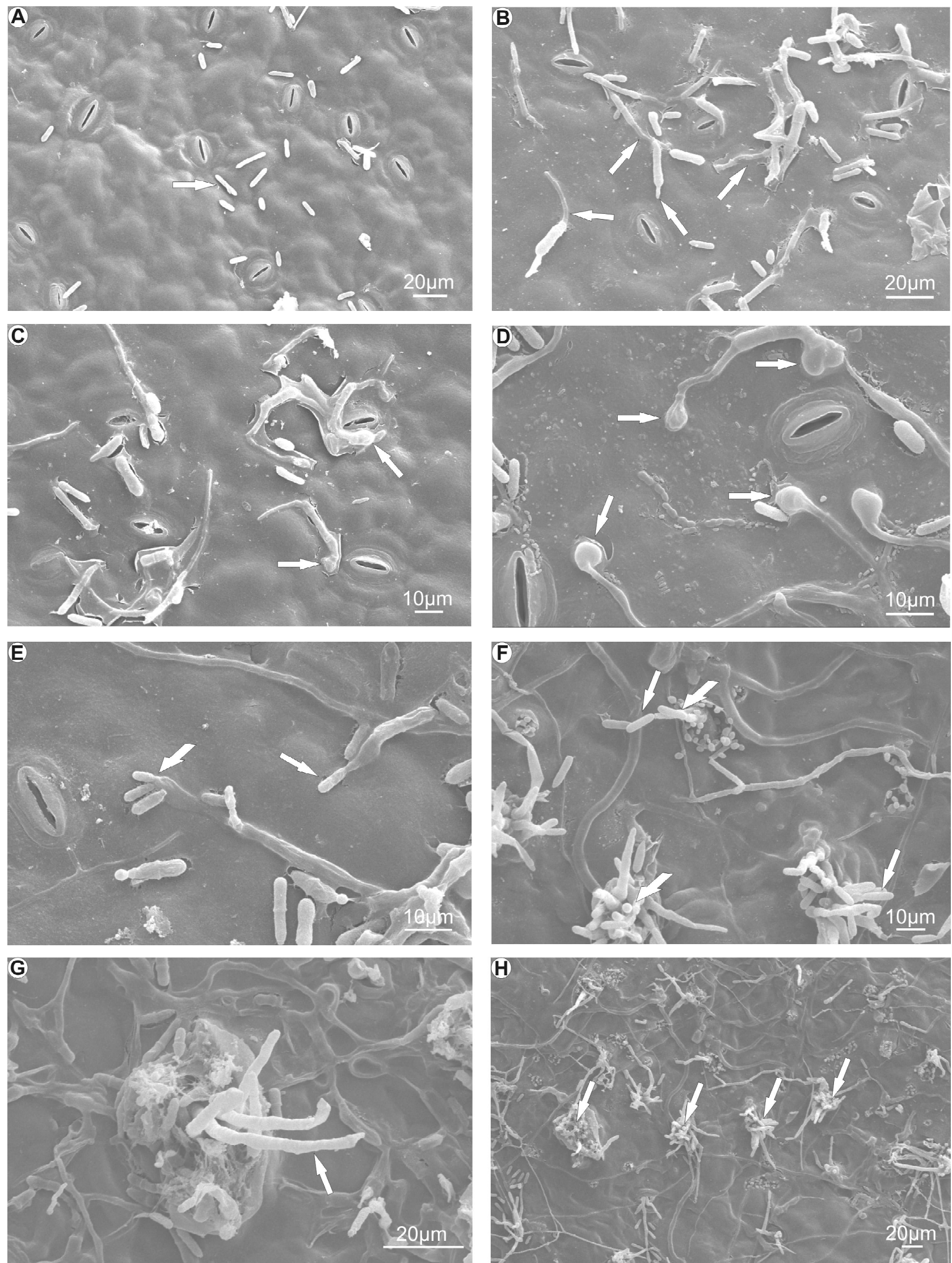

Figura 2. Eletromicrografias de varredura nos eventos de penetração, colonização e reprodução do isolado J-I6 de Colletotrichum gloeosporioides, obtido de folhas com sintomas de mancha manteigosa inoculado em folhas de cafeeiro. A: aderência de conídios em depressões da folha (setas); B: germinação de conídios (setas indicam tubos germinativos); C e D: formação de apressórios (setas); E e F: produção de conídios (setas) a partir de células conidiogênicas (setas largas); G: detalhe de um acérvulo com setas (setas) e H: produção de acérvulos (setas). 
de septo de 2 a 3 horas após a inoculação. Já em ensaios realizados por Mercure et al. (16), em membrana de diálise, usada como superfície artificial, foi observada após a inoculação, uma série de mudanças estruturais na germinação de conídios de C. truncatum patogênicos de plantas. Entre 1 a 2 horas, houve uma simples divisão mitótica no conídio e, de 2 a 3 horas, ocorreu iniciação do tubo germinativo e formação de um septo.

No isolado J-I2, observou-se o acúmulo de material extracelular, a "mucilagem", que pode favorecer a adesão dos conídios (Figura 1B), sendo também constatada no isolado J-I6, porém, em menor quantidade (Figura 2B). Vários autores relataram a importância da mucilagem, a qual está envolvida na sobrevivência, na dispersão e na patogenicidade de espécies do gênero Colletotrichum (3, 5, 6, 15). Essa matriz caracteriza-se por ser solúvel em água, possuir altos níveis de polissacarídeos e glicoproteínas como componentes principais e enzimas associadas, essenciais para a infecção das plantas hospedeiras $(3,5,6)$. Outra importante função, relacionada à mucilagem conidial, é o controle da germinação dos conídios, que quando em acérvulos ou suspensão com alta concentração, verifica-se autoinibição de germinação pela presença de substância denominada micosporina-alanina $(5,11$, 16).

Foi também observada a presença de mucilagem nos tubos germinativos e apressórios (Figuras 2C, 2D e 3E). Segundo Bergstrom \& Nicholson (5), essa é, geralmente, responsável pela aderência dessas estruturas nas superfícies do hospedeiro.

Com relação ao material vegetal estudado, não houveram diferenças significativas nos eventos de pré-penetração entre folhas de cafeeiro de plantas com sintoma da mancha manteigosa e folhas de plantas sadias inoculadas. Entre 3 e 5 horas após a inoculação, não se observou a germinação de conídios, independente da origem do isolado e do material inoculado.

Na literatura, verifica-se enorme variação, dentro do gênero Colletotrichum, no tempo de germinação, iniciando-se entre 4 a 96 horas após inoculação $(3,18,19,23)$. O início da germinação ocorreu entre 6 a 8 horas após a inoculação para os isolados da mancha manteigosa, quando alguns conídios emitiram um ou dois tubos germinativos (Figura 1C e 2B). A emissão de mais de um tubo germinativo é comumente observada para o gênero Colletotrichum $(12,16,18,20)$.

O tempo para germinação, para as diferentes combinações de Colletotrichum e outros hospedeiros é bastante variável $(14,15,16$ 17, 18). Segundo Orozco Miranda (19), conídios de Colletotrichum spp. isolados de cafeeiros iniciaram a germinação entre 5 a 8 horas em água destilada esterilizada a $25^{\circ} \mathrm{C}$, com a formação de um ou dois tubos germinativos. Pereira et al. (20) mencionaram que, na interação C. gloeosporioides-cafeeiro, a germinação dos conídios em hipocótilos ocorreu 6 horas após a inoculação, com ferimento e 12 horas em hipocótilos sem ferimentos. Resultado análogo foi encontrado por Lins et al. (12), que observaram germinação de conídio 5 horas após inoculações para C. gloeosporioides, 12 horas para C. acutatum e 24 horas para $C$. dematium inoculados em folhas e hipocótilos de plântulas de cafeeiro obtidas por cultura de embrião.

Para todos os isolados verificaram-se tubos germinativos formados somente nas extremidades, sendo, em sua maioria, longos, com a formação de apressório (Figuras 1D e 2D). Em alguns trabalhos, foi relatada a emissão de tubos germinativos nas extremidades, assim como lateralmente $(11,17)$, porém, neste estudo isso não ocorreu.

A formação de apressório ocorreu 12 horas após a inoculação, sendo a maioria formada em tubos germinativos longos direcionados às células-guardas do estômato (Figura 1D e 2D), porém, observaramse também apressórios em tubos germinativos curtos (Figura 3C e 3E). A maioria dos apressórios eram globosos a subglobosos, de contorno regular, entretanto, houve alguma variação na forma, em alguns casos (Figura 3D), em forma de vírgula e (Figura 3G) trilobados.

Lins et al. (12) observaram característica semelhante quanto à forma de apressório, relatando apressórios do tipo globosos a subglobosos, em forma de vírgula e trilobados, para $C$. dematium inoculados em cafeeiro. Pereira et al. (20) encontraram, em $C$. gloeosporioides, apressórios globosos a subglobosos.

Os apressórios têm como funções a adesão, penetração, sobrevivência e atuam como sítios de atividade química. Um apressório pode ser considerado como uma diferenciação morfológica (intumescimento) do ápice de uma hifa que forma uma elevação a partir da qual se origina uma hifa de penetração que invade o hospedeiro (2). Nair \& Corbin (18) relataram que, na espécie $C$. acutatum f.sp. pinea, a formação de apressório ocorreu 24 horas após a inoculação, ocorrendo a penetração da hifa de infecção. Conforme os autores, os apressórios podem se originar diretamente do conídio ou a partir do tubo germinativo. Segundo Chau \& Alvarez (9), na interação $C$. gloeosporioides e frutos de mamão, a hifa de infecção penetrou a cutícula, originada a partir de um apressório, a qual foi observada de 3 a 4 dias após a inoculação. Já Milholland (17) cita que a formação de apressórios de C. fragariae em pecíolos de morango ocorre entre 12 a 24 horas após a inoculação em tecidos de cultivares resistentes e suscetíveis.

A penetração, em sua maior parte, se deu por via direta e raramente pelos estômatos (Figuras 1E e 1F). Foi possível observar a degradação da cutícula no ponto de aderência dos apressórios (Figuras 2D e 3E). Segundo Perfect et al. (21), os eventos envolvidos na pré-penetração e penetração das espécies de Colletotrichum parecem ser análogos, porém, existem diferenças entre as espécies nos mecanismo de adesão, melanização e produção de cutinases para penetração na cutícula da planta.

Na interação Colletotrichum-cafeeiro, poucos são os trabalhos que evidenciam os processos de pré-penetração e penetração. Pereira et al. (20) verificaram a formação de apressórios 12 horas após inoculação, enquanto Lins et al. (12) observaram-na somente a partir de 24 horas, para $C$. gloeosporioides e 12 horas para $C$. acutatum. Segundo Chen (10) o tempo necessário para a formação de apressórios sobre folhas e frutos verdes de café inoculados com $C$. gloeosporioides ou $C$. kahawae é de 6 horas.

Nessa investigação foi possível observar a penetração de estômatos de folhas de cafeeiro inoculados com os isolados J-I2 e J-I6 sem a formação de apressório, fato já observado em outros patossistemas no gênero Colletotrichum $(22,23)$ (Figura 1E e 1F), concluindo que apressórios nem sempre são necessários para a penetração de espécies deste gênero. Conforme mencionado, existe variação quanto à forma de infecção das espécies de Colletotrichum. Entretanto, a formação de apressórios com sua respectiva melanização permite a penetração mecânica da hifa de infecção no hospedeiro e, segundo Bailey et al. (3), isso acontece para a maioria das espécies de Colletotrichum, principalmente aquelas que infectam tecidos novos.

Neste estudo os dois isolados de mancha manteigosa utilizados, apresentaram sucesso na colonização em tecidos foliares de folhas de café, ocorrendo formação de acérvulos (Figuras 1G, 1H, 2F, 2G e 2H), sendo mais abundante no isolado J-I2 (Tabela 1), o qual iniciou às 96 horas após a inoculação (Tabela 1), saindo pelas aberturas estomatais, produzindo conídios nas extremidades de setas (Figura 1G). Enquanto 

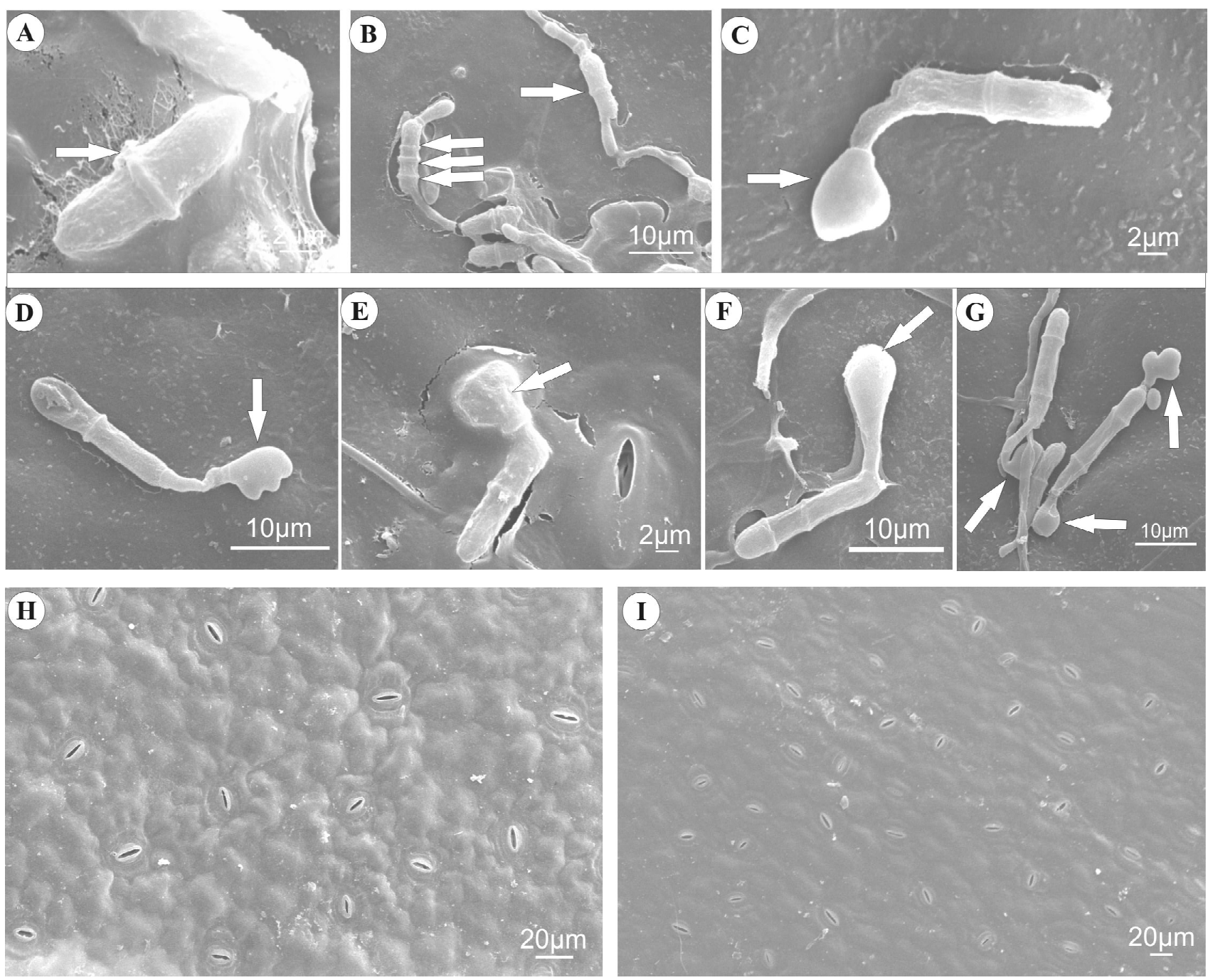

Figura 3. Eletromicrografias de varredura dos eventos de pré-penetração de isolados de Colletotrichum gloeosporioides, obtido de folhas com sintomas de mancha manteigosa, inoculado em folhas de cafeeiro. A e B: conídio antes da germinação mostrando a formação de septos (setas); C, D, E, F e G: formas de apressórios observadas (setas); H e I: testemunha inoculada com água.

o isolado J-I6 teve início às 144 horas após a inoculação. Para este isolado, 96 horas após a inoculação, se observou a esporulação diretamente em hifas de células conidiogênicas (Figura 2E). (INSERIR TABELA 1)

A formação de acérvulos em hipocótilos de cafeeiro (fase palito de fósforo) inoculados com C. gloeosporioides ocorreu nove dias após a inoculação nas interações compatíveis segundo Orozco Miranda (19). Pereira et al. (20) observaram que 72 horas é insuficiente para tal observação em hipocótilos de cafeeiro inoculados por este patógeno.

Segundo Lins et al. (12), a produção de acérvulos de $C$.

Tabela 1. Estruturas formadas por Colletotrichum gloeosporioides isolados de plantas de café e da antracnose da mangueira inoculada em folhas de cafeeiro, considerando a evolução no tempo para os diferentes eventos de penetração, colonização e conidiogênese.

\begin{tabular}{|c|c|c|c|c|c|c|c|}
\hline & \multicolumn{7}{|c|}{ ESTRUTURAS FORMADAS (tempo após inoculações) ${ }^{1}$} \\
\hline & & FSAG & GC & FA & PA & $\mathrm{PC}^{(\mathrm{H}, \mathrm{A})}$ & MP \\
\hline & \multicolumn{7}{|c|}{ Inoculação - folhas com sintoma da macha manteigosa } \\
\hline \multirow{5}{*}{$\begin{array}{l}\tilde{0} \\
\tilde{0} \\
\frac{\pi}{0} \\
0 \\
0\end{array}$} & $\mathrm{~J}-\mathrm{I} 6$ & 6 horas & 8 horas & 12 horas & 144 horas & $144 \operatorname{horas}^{(\mathrm{A})}$ & A \\
\hline & IM & 3 horas & 8 horas & 12 horas & - & 72 horas $^{(\mathrm{H})}$ & $\mathrm{AE}$ \\
\hline & & \multicolumn{6}{|c|}{ Inoculação - folhas sadias } \\
\hline & $\mathrm{J}-\mathrm{I} 6$ & 3 horas & 6 horas & 12 horas & 144 horas & 144 horas $^{(\mathrm{H}, \mathrm{A})}$ & $\mathrm{AE}$ \\
\hline & IM & 3 horas & 6 horas & 8 horas & - & 96 horas $^{(\mathrm{H})}$ & A \\
\hline
\end{tabular}

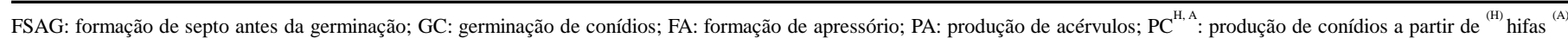

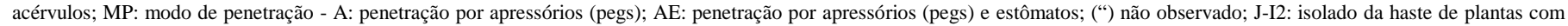
sintomas de mancha manteigosa; J-I6: isolado de hipocótilos com sintoma de mancha manteigosa; IM: isolado de folhas de mangueira com sintoma da antracnose. 

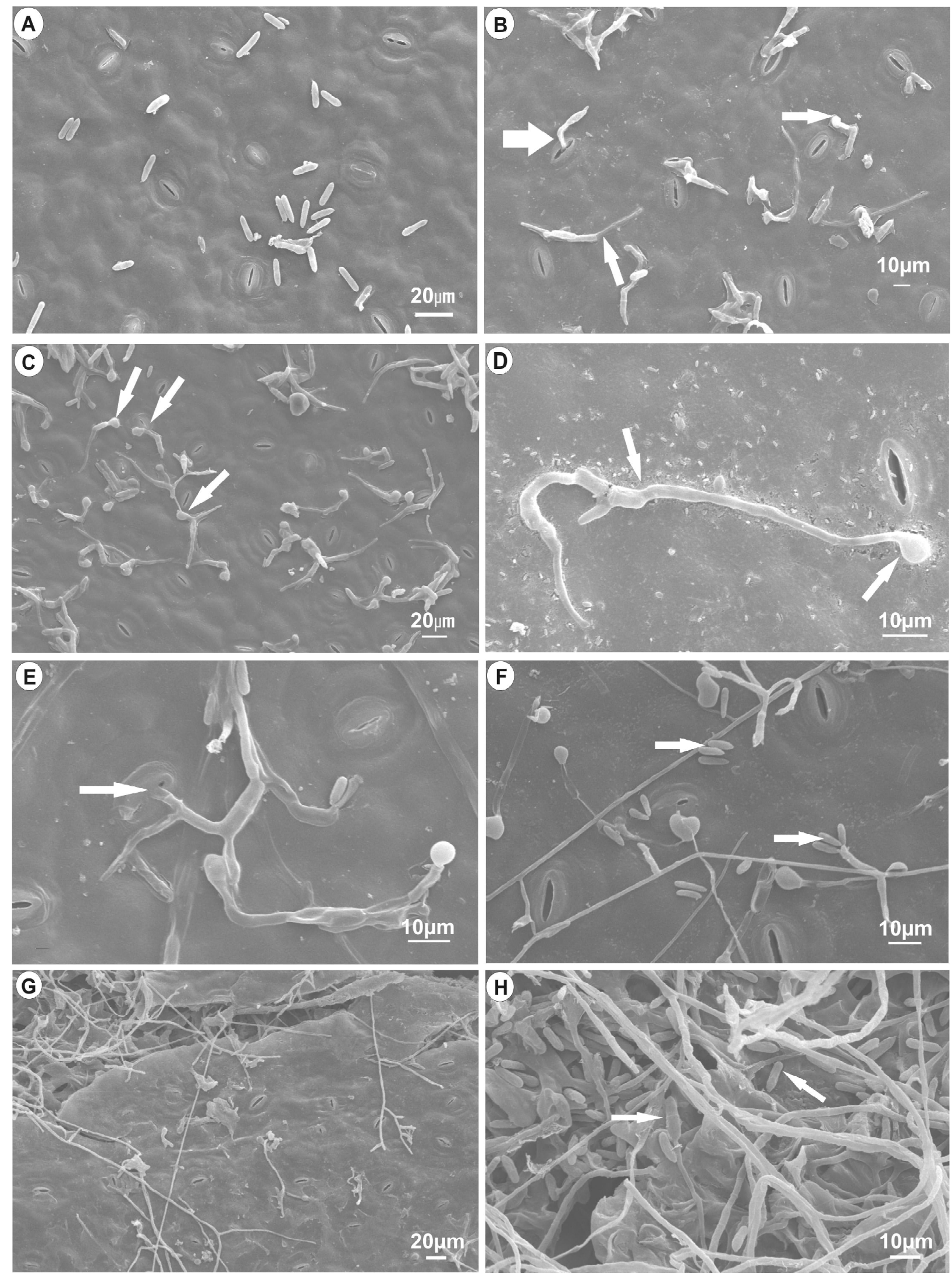

Figura 4. Eletromicrografias de varredura nos eventos de penetração, colonização e reprodução do isolado IM de Colletotrichum gloeosporioides, obtido de folhas de mangueira, inoculado em folhas de cafeeiro. A: aderência de conídios a cutícula; B: germinação dos conídios com formação de tubos germinativos (setas) e penetração via estômato (seta larga); C e D: formação de apressórios (setas); E: penetração via estômatos (seta); F: produção de conídios a partir de células conidiogênicas sem acérvulos; G: fratura em tecidos infectados mostrando o micélio sobre a cutícula da folha e dentro da fratura e H: detalhe da área com fratura observada em G, mostrando a colonização e produção de conídios a partir de células conidiogênicas sem acérvulos. 
gloeosporioides isolado de haste de cafeeiros com mancha manteigosa ocorreu 72 horas após a inoculação sobre plântulas desta espécie obtidos por cultura de embrião. A produção ocorreu mais tardiamente para isolados das espécies $C$. dematium obtidos de cafeeiros.

Dentre os isolados provenientes de plantas com sintomas de mancha manteigosa, verificou-se que o isolado da haste (J-I2) foi mais agressivo, destacando-se pela intensa colonização dos tecidos e produção de acérvulos e conídios (Figura 1H). Não foram observadas estruturas do patógeno ou de outro microrganismo na testemunha inoculada com água (Figuras 3H e 3I).

Eventos da infecção de C. gloeosporioides - isolado de folhas de mangueira

Os eventos de formação de septo e germinação para o isolado de C. gloeosporioides de folhas de mangueira foram semelhantes aos da mancha manteigosa.

O isolado IM, quando inoculado em folhas com sintomas de mancha manteigosa, iniciou a germinação e o crescimento do tubo germinativo 8 horas após a inoculação (Figuras 4A e 4B) e a formação de apressório a partir de 12 horas (Figuras 4C e 4D). Porém, quando inoculado em folhas sadias, houve antecipação na germinação dos conídios, bem como na formação de apressório, as quais ocorreram 6 e 8 horas após a inoculação, respectivamente (Tabela 1).

(INSERIR FIGURA 4)

Quanto ao tempo de formação de apressórios, este foi antecipado em 4 horas por este isolado, com os primeiros apressórios observados às 8 horas após a inoculação em folhas com sintomas da mancha manteigosa (Tabela 1).

Similarmente ao observado para os isolados J-I2 e J-I6, verificouse que o isolado IM raramente penetrou via estômato (Figura 4B e 4E). Entre 72 e 96 horas após a inoculação foram suficientes para a produção de conídios, sendo estes produzidos diretamente de hifas (Figura 4F). Não foi observada a produção de acérvulos até o final do experimento. Semelhante ao observado por Lins et al. (12), quando utilizaram isolado obtido de mangueira, inoculando hipocótilos e plântulas de café formadas por cultura de embrião e verificaram que o mesmo não formou acérvulos, sendo a produção de conídios observada diretamente de hifas.

Com 240 horas após a inoculação, constatou-se produção de conídios, com muitas hifas saindo de fraturas dos tecidos foliares, denotando sucesso na colonização pelo fungo (Figuras $4 \mathrm{G} \mathrm{e} 4 \mathrm{H}$ ).

Conídios de isolados de C. gloeosporioides de mangueira e cafeeiro são capazes de penetrar e colonizar folhas destacadas de cafeeiros, da cultivar Catucaí Vermelho, com e sem sintomas de mancha manteigosa. Apenas os isolados de cafeeiro com sintomas de mancha manteigosa foram capazes de produzir acérvulos, enquanto que os isolado de mangueira produziu conídios diretamente em hifas conidiogênicas sem a produção de acérvulos.

\section{AGRADECIMENTOS}

À FAPEMIG pelo apoio financeiro na manutenção dos equipamentos do LME/Ufla.

\section{REFERÊNCIAS BIBLIOGRÁFICAS}

1. Alves, E. Curso introdutório à microscopia eletrônica de varredura. Lavras, MG: FAEPE, UFLA, 2005. 43 p. Apostila.
2. Amorim, L. Colonização e reprodução. In: Bergamin Filho, A.; Kimati, H.; Amorim, L. Manual de fitopatologia: princípios e conceitos. 3. ed. São Paulo: Agronômica Ceres, 1995. v. 1 , cap. 16, p. 309-324.

3. Bailey, J. A.; O'Connel, R. J.; Pring, R. J.; Nasch, C. Infection strategies of Colletotrichum species. In: Bailey, J. A.; Jeger, M. J. (Ed.). Colletotrichum biology, pathology and control. Kew: CAB, 1992.

4. Barguil, B. M. Indução de resistência e reação de cultivares de Coffea arabica L. a Phoma costarricencis Echandi. 2004. 64 p. Dissertação (Mestrado em Fitopatologia) - Universidade Fedral de Lavras, Lavras, MG

5. Bergstrom, G. C.; Nicholson R. L. The biology of corn anthracnose: knowledge to exploit for improved management. Plant Disease, St. Paul, v. 83, n. 7, p. 596-608, 1999.

6. Bergstrom, G. C.; Nicholson R. L. Invertase in the spore matrix of Colletotrichum graminicola. Phytopathology Zeitschrift, Berlin, v. 102, n.2, p. 139-147, 1981

7. Brown, G. E. Ultrastructure of penetration of ethylene-degreened Robinson tangerines by Colletotrichum gloeosporioides. Phytopathology, St. Paul, v. 67, n. 3, p. 315-320, 1977.

8. Chau, K. F.; Alvarez, A. M. A histological study of anthracnose on Carica papaya. Phytopathology, St. Paul, v. 73 , n. 8 , p. 1113-1116, 1983 .

9. Chen, Z. Morphocultural and pathogenic comparisons between Colletotrichum kahawae and Colletotrichum gloeosporioides isolated from coffee berries. 2002. 163f. Tese (Doutorado em Engenharia Agronômica) - Instituto Superior de Agronomia da Universidade Técnica de Lisboa, Lisboa.

10. Daykin, M.; Milholland, R. B. Histopathology of ripe rot caused by Colletotrichum gloeosporioides on muscadine grape. Phytopathology, St. Paul, v. 74, n. 11, p. 1339-1341, 1984.

11. Leite, B.; Schadeck, R. J. G. Micosporinas: a importância no processo de germinação de esporos em fungos. Fitopatologia Brasileira, Brasília, v. 21, n.2, p. 149-155, 1996.

12. Lins, S. R. O.; Abreu, M. S.; Alves, E. Estudos histopatológicos de Colletotrichum spp. em plântulas de cafeeiro. Fitopatologia Brasileira, Brasília, v. 32, n. 6, p. 488-496, 2007.

13. Lopez, A. M. Q. Taxonomia, patogênese e controle de espécies do gênero Colletotrichum. Revisão Anual de Patologia de Plantas, Passo Fundo, v. 9, p. 291-338, 2001.

14. Marks, G. C.; Berbee, J. C.; Riker A. J. Direct penetration of leaves of Populus tremuloides by Colletotrichum gloeosporioides. Phytopathology, St. Paul, v. 55, n. 4, p. 408-412, 1965.

15. Mendgen, K.; Deising, H. Infection structures of fungal plant pathogens a cytological and physiological evaluation. New Phytologist, Cambridge, v. 124, n. 2, p. 193-213, 1993.

16. Mercure, E. W.; Kunoh, H.; Nicholson, R. L. Adhesion of Colletotrichum graminicola conidia to corn leaves: a requirement disease development. Physiological and Molecular Plant Pathology, London, v. 45, n. 6, p. 407-420, 1994.

17. Milholland, R. D. Histopathology of strawberry infected with Colletotrichum fragariae. Phytopathology, St. Paul, v. 72, n. 11, p. 1434-1439, 1982.

18. Nair, J.; Corbin, J. B. Histopathology of Pinus radiata seedlings infected by Colletotrichum acutatum f. sp. pinea, Phytopathology, St. Paul, v. 71, n. 8, p. 777-783, 1981.

19. Orozco Miranda, E. F. Caracterização morfológica, molecular, bioquímica e patogênica de isolados de Colletotrichum spp. associados ao cafeeiro em Minas Gerais e Comparação com Colletotrichum kahawae. 2003. 147f. Tese (Doutorado em Fitopatologia) - Universidade Federal de Lavras, Lavras, MG.

20. Pereira, I. S.; Abreu, M. S.; Alves, E.; Ferreira, J. B. Estudos histopatológicos da interação Colletotrichum gloeosporioides - cafeeiro. Bragantia, São Paulo, v. 68, p.53-61, 2009.

21. Perfect, S. E.; Hughes, H. B.; O'Connell, R. J.; Gren, J. R. 
Colletotrichum: a model genus for studies on pathology and fungal-plant interactions. Fungal Genetics and Biology, San Diego, v. 27, n. 2/3, p. 186-198, 1999.

22. Porto, M. D. M.; Grau, C. R.; De Zoeten, G. A.; Gaard, G. Histopathology of Colletotrichum trifolii on alfalfa. Phytopathology, St. Paul, v. 78, n. 3, p. 345-349, 1988.

23. Roberts, R. G.; Snow, J. P. Histopathology of cotton boll rot caused by Colletotrichum capsici. Phytopathology, St. Paul, v. 74, n. 4, p. 390-397, 1984.

24. Voltan, R. B. Q.; Cabral, L. P.; Paradela Filho, O. Avaliação preliminar do efeito do Colletotrichum spp. na estrutura de plantas de cafeeiro. In: Congresso brasileiro de pesquisas cafeeiras, 28., 2002, Caxambu. Trabalhos apresentados. Rio de Janeiro: MAPA/Procafé, p. 364-365, 2002. 